\title{
Crisis social, espiritualidad y herejía en la diócesis de Urgel (siglos XII-XIII). Los orígenes y la difusión de la herejía cátara en la antigua diócesis de Urgel
}

\author{
Carles Gascón Chopo
}

\begin{abstract}
RESUMEN
ABSTRACT

El fenómeno de la difusión de la herejia de los cátaros sobre territorio catalán es un tema que ha estimulado numerosas imaginaciones a lo largo de los años, sin que haya sido objeto de un tratamiento historiográfico riguroso.

El presente trabajo pretende establecer unas pautas, basadas en

el estudio de la evolución de la conflictividad social y de las mentalidades en la antigua diócesis de Urgel, para explicar las causas y la dinámica inicial de la introducción de estas doctrinas disidentes en la

The phenomenon of the spread of the Cathar Heresy on Catalan territory has fired many imaginations over the years, but it has never been object of a rigorous historiographical treatment. The aim of the present work is to establish some guidelines, based on the study of the evolution of social tensions and mentality in the ancient Diocese of Urgel, in order to explain the causes and the initial dynamics of the introduction of these dissident doctrines in the area of maximum developement of theirs on the South part of the Pyrenees.
\end{abstract}

que sería su área de máximo desarrollo al sur de la cordillera pirenaica.

\section{PALABRAS CLAVE}

Herejia, catarismo, Cataluña, Diócesis de Urgel, conflictividad social.

\section{KEYWORDS}

Heresy, catarism, Catalonia, Diocese of Urgel, social conflict. 


\section{INTRODUCCIÓN}

A lo largo de las últimas cuatro décadas, el fenómeno del catarismo se ha convertido en un producto de consumo cultural masivo, especialmente en las regiones del sur de Francia que conocieron el mayor florecimiento de esta herejía a lo largo de los siglos XII y XIII. Sin embargo, la enorme popularidad que se ha desarrollado en torno a este fenómeno ha derivado en demasiadas ocasiones en una vulgarización excesiva de sus contenidos, dando alas a la concurrencia de una literatura paracientífica o divulgativa de escasa calidad, poco dispuesta a respetar el rigor histórico, animada por la demanda creciente de un público atraído por el mundo de lo esotérico y potenciada por una explotación turística intensiva.

En el ámbito catalán, el desarrollo de una industria cultural vinculada a la impronta histórica dejada por la presencia de los cátaros es un fenómeno mucho más incipiente que en la vertiente francesa, pero con unas potencialidades que están empezando a ser explotadas por diversos agentes culturales, especialmente en el área pirenaica. Con todo, la popularidad del catarismo entre el público catalán no se ha visto correspondida por el momento con un interés paralelo en los círculos académicos vinculados a la universidad. En este sentido, cabe destacar la falta de estudios de carácter científico sobre este tema desde que Jordi Ventura escribiera lo principal de su obra a principios de los años sesenta. Por su parte, la concurrencia de ciertas obras de carácter esencialmente divulgativo aportan muy poco o nada nuevo al discurso historiográfico.

\subsection{La dimensión histórica del catarismo}

La historiografía actual tiende a englobar bajo el término catarismo al conjunto de creencias adoptadas por un nutrido grupo de sectas religiosas desarrolladas en el seno de la cristiandad medieval a lo largo de los siglos que discurren entre los años 1000 y 1300 y que, más allá de ciertas peculiaridades regionales o evolutivas, tienen como común denominador la reinterpretación de los fundamentos teológicos del cristianismo bajo una óptica dualista, aceptando la existencia simultánea de un doble principio de la creación. La suerte de dichas comunidades heréticas a lo largo de estos tres siglos fue muy desigual, y solamente en casos muy concretos llegaron a articular una estructura orgánica de tipo eclesial, siendo el proyecto más evolucionado el de la Occitania de los siglos XII y XIII, a partir del cual se produciria la difusión del catarismo en Cataluña.

Abreviaturas empleadas: ACU, Archivo Capitular de Urgel; AEG, Archivo Episcopal de Girona; BN, Biblioteca Nacional de Paris; LDEU, Liber Dotaliarum Ecclesiae Urgellensis (Cartulario de la catedral de Ja Seu d'Urgell). 
A lo largo de su accidentada historia, el catarismo demostraría una extraordinaria capacidad de respuesta a las principales inquietudes espirituales de la sociedad en cada momento sin la coerción de una rígida superestructura eclesiástica, hecho que supuso en algunas áreas concretas la adhesión de grandes sectores de la sociedad, y ello pese al mantenimiento de ciertos aspectos arcaizantes más propios, según el historiador André Vauchez, del movimiento monástico del siglo $X I$ que del nuevo universo espiritual de los siglos XII y XIII, manifestados especialmente en el elitismo de los perfectos, que eran los miembros del orden sagrado del catarismo y los únicos destinados a la salvación ${ }^{2}$.

La gran capacidad de sincretismo demostrada por el catarismo permitió a los seguidores de esta herejía adoptar nuevos planteamientos que daban respuesta a las grandes inquietudes religiosas de una sociedad que estaba experimentando cambios notables con el desarrollo de nuevos modelos económicos y organizativos. El crecimiento de las ciudades y de la economía de mercado y la consolidación del régimen feudal provocaban grandes tensiones sociales acompañadas de una profunda crisis de conciencia que tendría su reflejo en la evolución de las antiguas concepciones religiosas, aportando una serie de nuevas inquietudes que introducirían una serie de cambios trascendentales en la espiritualidad cristiana medieval.

\subsection{La historiografía del catarismo en Cataluña}

La mayor parte de nuestros conocimientos actuales sobre la difusión de la herejía cátara sobre el territorio catalán proceden de los trabajos del historiador Jordi Ventura i Subirats, sin cuyas aportaciones el capítulo del catarismo en Cataluña se limitaría a unas pocas menciones prácticamente inconexas. La producción de Jordi Ventura en torno a este tema y algunas de sus implicaciones es singularmente prolífica. Sin embargo, la mayor parte de sus aportaciones se concentra en uno de sus primeros trabajos, El catarismo en Cataluña (1960), complementándose con nuevos datos que aparecen puntualmente en artículos posteriores, particularmente en La valdesia de Cataluña (1962).

Como queda dicho, el conocimiento que se tenía con anterioridad a la obra de Ventura sobre el catarismo en Cataluña, se limitaba a una escasa serie de datos en torno a la figura del vizconde Arnau de Castellbò y de sus sucesores, los condes de Foix, puestos en relieve en Relations politiques des comtes de Foix avec la Catalogne jusqu'au commencement du XIV siècle (1896), obra del historiador francés Charles Baudon de Mony y en la Investigación histórica sobre el vizcondado de Castellbó (1900), del catalán

A. Vauchez, La spiritualité du Moyen Age occidental, Éditions du Seuil, Paris 1994, pags. 109-110. 
Joaquim Miret i Sans, combinados con otras informaciones puntuales extraídas de fondos diversos.

Por lo tanto, la obra de Jordi Ventura se convierte prácticamente en el único punto de referencia para el estudio del catarismo en Cataluña, y por ello, aunque sus principales aportaciones datan de principios de los años sesenta, mantienen todavía plena vigencia en la actualidad. La obra de Ventura es el producto de una ingente tarea de erudición, en el trancurso de la cual investigó todos los fondos documentales e historiográficos conocidos. A partir de su vaciado y su análisis, el autor construyó un discurso de corte nacionalista, vertebrado por la voluntad de presentar el catarismo catalán como la expresión espiritual de una comunidad de cultura y de civilización existente a caballo de la cordillera pirenaica, que experimentaría una difusión notable en la vertiente meridional de los Pirineos, y cuya plasmación política bajo los auspicios de los condes de Barcelona se vería truncada por la cruzada contra los cátaros en el Languedoc a principios del siglo XIII. En ocasiones incluso, Jordi Ventura llega a forzar en su discurso la interpretación de los datos extraídos de las diversas fuentes para acomodarlos a su particular línea interpretativa.

Sin embargo, la obra de Jordi Ventura tiene la virtud de ser la primera, y hasta ahora la única obra de investigación que propone una síntesis sobre el catarismo catalán en su conjunto. Pese a todas sus cargas interpretativas, justificables por las limitaciones del análisis historiográfico del momento y por los condicionantes de un determinado ambiente académico e intelectual, la gran cantidad de datos que aporta convierten esta obra en un punto de partida ineludible para emprender cualquier estudio sobre el tema.

Hasta prácticamente la década de los noventa los únicos trabajos publicados sobre el catarismo en Cataluña fueron obra de Jordi Ventura. Sin embargo, en la última década, el interés que ha despertado el fenómeno del catarismo entre el público catalán ha fomentado la aparición de una serie de novedades editoriales que priman el espíritu divulgativo al análisis historiográfico. En términos generales, la aportación de este tipo de obras es muy escasa. Con todo, y aunque no se trate de un estudio historiográfico propiamente dicho, podríamos hablar de la obra Els càtars, problema religiós, pretext politic, de Jesús Mestre, publicada en su primera edición en 1994. Se trata de una obra que constituyó en su momento un gran éxito editorial y que lanzó a su autor a la fama entre el público catalán. La obra de Mestre fue la primera de una larga serie de publicaciones de autores catalanes sobre el tema del catarismo, de aparición más o menos periódica y de vocación esencialmente divulgativa. En esta obra, el autor desarrolla una monografía sobre la historia de la herejía cátara desde sus orígenes hasta la conquista de la ciudadela de Montsegur por parte de las tropas francesas en 1244, dedicando un capítulo entero a explicar la relación de la herejía con Cataluña. A lo largo de sus páginas, Mestre pone en cuestión la validez del modelo propuesto por Jordi Ventura, minimizando el fenómeno 
de la difusión del catarismo en Cataluña con el argumento de la presencia de una autoridad fuerte en la figura de los reyes de la Corona de Aragón, capaces de imponer un principio de centralización en las tierras catalanas que permitiría ejercer una represión efectiva e impediría el establecimiento de un gran número de herejes, contrariamente a lo sucedido en el Languedoc. Es por todo ello que Jesús Mestre minimiza el fenómeno del catarismo catalán, reduciéndolo prácticamente a una frívola moda adoptada por ciertas personalidades de la nobleza pirenaica, con un escaso eco en el conjunto de la sociedad catalana.

Paradójicamente, las líneas defendidas por Jordi Ventura y Jesús Mestre, irreconciliables en apariencia, parten de una misma premisa, señalando en la figura del rey de la Corona de Aragón al único agente capaz de fiscalizar la entrada del movimiento herético en Cataluña, y reduciendo la sociedad catalana medieval a un rol totalmente pasivo. Por otra parte, ambos historiadores confían en que el descubrimiento de nueva documentación inédita permitirá algún día dar un giro decisivo a la investigación. Pese a todo, las aportaciones de Jesús Mestre suponen un primer apunte crítico a la obra de Ventura después de tantos años, que permitirá la reapertura de un cierto ambiente de debate en torno al tema, ambiente que sin duda será beneficioso para la aportación de nuevas líneas interpretativas.

\subsection{La diócesis de Urgel}

La facilidad de realizar un seguimiento pormenorizado de la documentación de los siglos XII y XIII del Archivo Capitular de Urgel, próximo al domicilio del que suscribe estas líneas, combinada con la complejidad de gestionar el volumen ingente de datos que hubiera supuesto la investigación del fenómeno cátaro en la totalidad de Cataluña, proyecto a todas luces excesivo para un trabajo de naturaleza más modesta que una tesis doctoral, aconsejaron delimitar un ámbito más reducido, definido por los territorios que conformaban la diócesis de Urgel en el período medieval, área que experimentaría el máximo desarrollo de la herejía cátara al sur de los Pirineos.

Como en el resto de las diócesis catalanas, la configuración territorial de la diócesis de Urgel en la Edad Media depende estrechamente de las líneas de la expansión condal sobre las comarcas musulmanas del sur. De este modo, la conquista definitiva de la ciudad de Balaguer en 1105, fija su límite meridional al cerrar la expansión de este condado. Desde los tiempos carolingios, el obispado de Urgel comprendía los condados de Pallars, Urgel y Cerdaña, con lo cual su crecimiento seguiría las líneas de expansión de estas tres demarcaciones sobre tierras musulmanas. La conquista de Balaguer supondría el fin de este proceso y la fijación de unos límites diocesanos que permanecerían estables durante el resto del medievo. 
La diócesis de Urgel en su etapa medieval era la más extensa de Cataluña, comprendiendo todo el cuadrante noroccidental del país a excepción del Valle de Arán, que permanecería bajo la autoridad del obispo de Comenge hasta el siglo XIX. Se trata de un territorio esencialmente montañoso, con la cabecera formada por los altos picos del Pirineo axial, seguidos por las laberinticas sierras prepirenaicas del Cadí, el Boumort y el Montsec, que prolongan sus contrafuertes más externos hasta prácticamente hasta las puertas de la ciudad de Balaguer. Solamente en su extremo más meridional esta abrupta orografía da paso a los primeros llanos de la Depresión del Ebro. Dentro de este territorio, los principales cursos fluviales se abren paso a través de los sistemas montañosos en sentido meridiano. Solamente el Segre, desde su nacimiento en la actual Cerdaña francesa hasta la Seu d'Urgell aproximadamente, discurre en un sentido este-oeste, configurando el amplio valle de la Cerdaña. La mayor parte de estos cursos fluviales pertenecen a la cuenca del Ebro, pero los territorios que configuran la franja sudoriental de la diócesis, centrados en torno a las villas de Berga, Solsona y Cardona están bañadas por los cursos alto y medio del Llobregat y de su afluente el Cardener.

\section{LA CONCRECIÓN DE LAS BASES SOCIALES E IDEOLÓGI- CAS FAVORABLES AL ARRAIGO DE LA HEREJIA EN LA DIÓCESIS DE URGEL}

\subsection{El alcance de la reforma gregoriana en la diócesis de Urgel}

El proceso histórico conocido bajo la denominación de reforma gregoriana consistió en la aplicación de un conjunto de innovaciones en el funcionamiento de la Iglesia romana, propiciadas desde la sede apostólica con la finalidad de establecer un primado efectivo de la figura del papa sobre el conjunto de la Iglesia occidental. Para ello era necesario acabar con la injerencia laica en el gobierno de la Iglesia, hecho que provocaría una fuerte reacción por parte de un poder temporal celoso de unas prerrogativas que venía ejerciendo desde hacía varios siglos, y recuperar a las jerarquías eclesiásticas locales de sus limitados ámbitos de acción para vincularlas a un aparato de poder mucho más amplio dirigido desde Roma. Con pocos más activos que la propia autoridad moral del papa, el partido reformista supo canalizar eficazmente el nuevo clima espiritual manifestado por sectores cada vez más amplios de la cristiandad occidental, para establecer un control más estrecho del clero mediante la reforma de aquellas costumbres que se mostrabar particularmente escandalosas, y que además fomentaban la progresiva feudalización del estamento clerical y su consiguiente alejamiento de la órbita pontificia.

El movimiento reformista en la diócesis de Urgel se vincularía estrechamente a la voluntad de dos grandes prelados, que aprovecharon sus largos 
pontificados para desplegar sus aspectos principales por toda la demarcación diocesana. Se trata del obispo Bernat Guillem (1075-1092), que realizó un cambio brusco de tendencia con respecto a su antecesor el simoníaco Guillem Guifré, poco favorable a la reforma, y el obispo Ot (1095-1122), venerado como santo patrón de la diócesis desde 1133. Ambos obispos, separados por el breve pontificado de Guillem Arnau de Montferrer, destacaron por su lucha contra el bajo nivel moral del clero y por su discurso contrario a la injerencia de los laicos en los asuntos de la Iglesia, si bien, consta que el obispo Ot favoreció cierta participación de los seglares en el culto mediante la promoción de cofradias mixtas de clérigos y laicos. Por otra parte, ambos obispos favorecieron el despliegue del movimiento canonical en la diócesis, que tuvo su momento álgido, precisamente, en el medio siglo aproximado que transcurre durante los dos pontificados. Las canónicas de Cardona, Äger, Montmagastre, Solsona u Organyà, distribuidas por buena parte de la demarcación urgelense adoptarían la regla de San Agustín y promoverían la difusión de los principios reformistas por el territorio diocesano.

Siguiendo la tónica general de Occidente, la Iglesia de Urgel emerge del período más comprometido de la reforma notablemente fortalecida. Durante el medio siglo que transcurre a caballo de 1100 aproximadamente, los obispos urgelenses se han adaptado perfectamente a los nuevos aires que llegan desde Italia y han sabido canalizar las principales corrientes de este movimiento multiforme para convertir su Iglesia en una entidad sumamente rica y poderosa. El prestigio alcanzado por la Iglesia de Urgel y sus obispos reformistas (recordemos la beatificación del obispo Ot en 1133) redundó en una enorme oleada de donaciones piadosas, generalmente materializada en la cesión a dicha institución de tierras o de rentas agrarias de diversa naturaleza, particularmente en el área norteña de la diócesis. Todo ello, combinado con las rentas procedentes del gran número de templos restituidos al dominio episcopal o de otras entidades religiosas, y con las facilidades cada vez mayores de convertir la renta agraria en moneda ante la progresiva expansión de la economía de mercado, permitiría la acumulación de enormes sumas de dinero a manos de la Iglesia diocesana.

Al menos una parte de estos recursos fueron invertidos en procurar un mayor esplendor de la liturgia cristiana. Comenzando por la nueva catedral de la Seu d'Urgell, iniciada hacia 1116 a instancia del obispo Ot, los muros de los templos se pueblan de ricos ciclos escultóricos o pictóricos, destinados a facilitar la comprensión de la Palabra de Dios entre los fieles, y los altares deslumbran a la comunidad de los creyentes al llenarse de lujosos objetos litúrgicos e imaginería en los que abundaba el oro y la plata, objetos que convertían a los templos mejor dotados en verdaderas reservas de valor. Otra parte de los ingresos de la Iglesia iban destinados a la manutención de sus miembros, que gracias a ellos podían vivir de un modo más desahogado que la mayoría de los laicos y, en el caso de las comunidades religiosas más adineradas, como lo eran las principales canónicas y algunos 
monasterios, no era infrecuente el lujo, la ostentación e incluso una falta de decoro que no dejaba de escandalizar a los espíritus más sensibles, influidos por un nuevo panorama espiritual más exigente con las costumbres del clero y proclive a revalorizar la pobreza como medio de salvación.

Sin embargo, el principal motivo de discordia que propiciaría a la larga la ruptura de la Iglesia de Urgel con una parte importante de sus fieles tendría su origen en la competencia desplegada con los laicos por el control de las rentas generadas por las iglesias de la diócesis, particularmente de los diezmos, que ingresaban una parte proporcional de las rentas agrarias generadas en cada parroquia. En el momento álgido de la reforma, el discurso de la libertad de la Iglesia frente a la acción de los laicos permite la restitución, bajo un grado de espontaneidad muy diverso, de gran número de templos con sus rentas anexas a la jurisdicción eclesiástica. Con todo, a medida que pase el tiempo y la Iglesia de Urgel sea cada vez más fuerte y poderosa, el grado de coerción para lograr la restitución de las iglesias será mayor. Como en buena parte de Occidente el estamento aristocrático sería el más perjudicado, particularmente los miembros de la baja nobleza, señores de castillos o caballeros, para los cuales la pérdida de lo que era una valiosa fuente de ingresos podía hacer tambalear sus siempre precarias economias. Pero las restituciones forzosas de los templos parroquiales también irían en detrimento de numerosas comunidades rurales de los altos valles pirenaicos, por lo general poco permeables a la expansión del dominio feudal, que conservaban todavía en pleno siglo XII sus derechos consuetudinarios sobre los antiguos templos que habían edificado sus antepasados. En muchos casos, era el propio grupo aldeano el que gestionaba los diezmos e incluso tenía la capacidad de elegir a su párroco, que recibía a posteriori la confirmación del obispo ${ }^{3}$. Según el historiador Pierre Bonnassie, este régimen de propiedad comunal sobre los templos del área pirenaica había sobrevivido a los embates de la aristocracia laica sobre la propiedad pública desde la segunda mitad del siglo $\mathrm{XI}^{4}$. Probablemente, el caso de las parroquias andorranas sea el mejor estudiado ${ }^{5}$, aunque la documentación nos da pistas sobre situaciones similares en otras parroquias de esta zona del Pirineo axial.

- Para conocer con más detalle las características de este particular modelo de gestión popular de los templos parroquiales en las comunidades pirenaicas véase $C$. Baraut, "Les actes de consagracions d'esglésies del bisbat d'Urgell (segles IX-XII)", Urgellia, 1, la Seu d'Urgell 1978, págs. 11-182.

"Véase Pierre BONNASSIE, Del esclavismo al feudalismo en Europa occidental, Crítica, Barcelona 1993, págs. 246-263.

En la concordia con los vecinos de los valles de Andorra en 1163. éstos se obligan a librar sus iglesias al obispo, cognoscentes nefarium et iniustum esse quod laici teneant ecclesias vel clerici per manus laicorum, sin más, ACU, LDEU, I, fol. 244r-245v, doc. 844, ed. C. Baraut, "Els documents, dels anys 1151-1190, de l'Arxiu Capitular d'Urgell», Urgellia, 10, la Seu d'Urgell 1990-1991, págs. 7-349, doc. 1.571. Para más información sobre el particular proceso de feudalización en los valles de Andorra véase Roland Viader, "Andorra i la mutació feudal", L'Avenç, núm. 202, 1997, págs. 52.55. 
La pugna por la posesión de los templos parroquiales y sus diezmos provocará, pues, los primeros desencuentros de la Iglesia urgelense con varios sectores de la sociedad laica de la diócesis. En el caso de la aristocracia, este conflicto incipiente se agravará con el progresivo incremento de las capacidades jurisdiccionales de la Iglesia de Urgel en el marco de una sociedad que se deslizaba rápidamente hacia un modelo de relaciones típicamente feudales. Apoyada en sus dominios ya consolidados durante el siglo XI, particularmente la propia villa de la Seu d'Urgell, pero también otros, como el castillo de Tuixén, en el valle de la Vansa, a partir de principios del siglo XII la Iglesia de Urgel experimenta un gran incremento de su jurisdicción en la llanura en la que se asienta la sede diocesana a partir de compras o donaciones piadosas de tierras y castillos. Este proceso, paralelo al progresivo retraimiento de la autoridad de los condes de Urgel a las tierras nuevas del sur del condado, culmina con la cesión al obispo de Urgel de la jurisdicción sobre los valles de Andorra en el año $1133^{6}$. Las nuevas responsabilidades asumidas por la Iglesia de Urgel en la cabecera pirenaica de la diócesis arrastrarían a los sucesivos obispos hacia una dinámica feudal muy complicada que acabaria por escapárseles de las manos.

El enorme grado de poder obtenido por los obispos de Urgel sobre los territorios septentrionales de su diócesis contrasta con la escasa influencia que, por lo general, pudieron desplegar sobre el área meridional. La gran ampliación de los límites diocesanos experimentada con los avances cristianos del siglo XI desbordó el rudimentario aparato administrativo diocesano, poniendo de manifiesto unas carencias que serian subsanadas con la acción de las nuevas fundaciones canonicales que, no sin tensiones con la sede episcopal, establecen en el sur un sistema de patronazgos eclesiásticos que restan capacidad de acción al obispo. En el caso más extremo, la colegiata de Sant Pere d’Àger conseguirá de Roma la condición de abadía exenta mantenida hasta 1874 , a pesar de sus querellas recurrentes con los obispos de Urgel y de Lérida. No hay que perder de vista este contraste entre la escasa capacidad de acción episcopal sobre los territorios del sur de la diócesis y el enorme grado de intervención sobre la cabecera pirenaica, ya que, como se verá, coincide a grandes rasgos con la diversidad del grado de implantación de la herejía cátara en la misma.

\subsection{La evolución de la espiritualidad laica en la diócesis de Urgel en el siglo XII}

Durante los siglos XI y XII, las tensiones provocadas por las transformaciones socioeconómicas experimentadas en Occidente generaron un clima de inquietud que, en el seno de una sociedad teocéntrica, con todos los ám-

ACU, LDEU. I. fol. 168r, doc. 493, ed. C. BARAUT, "Els documents, dels anys 1101-1150, de I'Arxiu Capitular d'Urgell", Urgellia, 9, la Seu d'Urgell 1988-1989, págs. 8-312, doc. 1.424. 
bitos vivenciales individuales y colectivos profundamente sacralizados y cualquier atisbo de reflexión intelectual estrechamente mediatizado por el peso abrumador de lo trascendente en todas sus expresiones, no podía manifestarse de otro modo que a través de un desasosiego espiritual que alcanzaría tanto a clérigos como a seglares y que, en buena medida, sería canalizado por las reivindicaciones de la Iglesia durante el período reformista. Superada la fase más crítica de la reforma, con una Iglesia muy fortalecida y su jerarquía muy beneficiada por el aumento de las temporalidades eclesiásticas, el alto clero se acomodaría rápidamente a la nueva situación, olvidando sus antiguas veleidades reformistas y, recluida en su preeminente posición social, excluyendo a los laicos de la institución que gobernaba. Del programa reformista solamente se conservaría una retórica hueca, destinada a justificar el predominio social de la Iglesia y a justificar unos intereses concretos.

Los espíritus más inquietos, defraudados por el giro que tomaba la postura de la jerarquía eclesiástica, buscarían nuevas vías de expresión de la espiritualidad que acabarían alimentando los grandes movimientos heterodoxos de los siglos XII y XIII. La mayor movilidad de la sociedad y la propia institucionalización de la Iglesia, con el incremento de las relaciones e intercambios entre los principales centros de creación intelectual de Occidente, facilitarían la difusión y la popularización de las nuevas formulaciones espirituales.

Los principales estímulos espirituales que agitarían las conciencias de los fieles durante los siglos XI y XII, giraban en torno al desarrollo de un rigorismo en las costumbres, con la revalorización de la austeridad y la pobreza bajo una nueva óptica evangélica, y también en torno a la cuestión de la participación directa de los laicos en los asuntos de la Iglesia y en la capacidad de influir en su propia salvación. Como queda dicho, esta nueva efervescencia espiritual recogia grandes tensiones que afloraban en la sociedad durante estos siglos, con el desarrollo de nuevos modelos sociales y económicos, y conocería una serie de manifestaciones muy diversas que serían asumidas por los principales movimientos heréticos del siglo XII, cuyo éxito dependería, precisamente, de su capacidad de conectar con las grandes aspiraciones de la espiritualidad popular.

Si bien estas nuevas experiencias maduraban en las regiones más desarrolladas de Occidente, donde las contradicciones económicas y sociales eran más acusadas y se manifèstaban con mayor virulencia, como sucedía en las áreas urbanizadas del norte de Italia, se difundirían rápidamente por todo el ámbito de la cristiandad latina, animadas por el desarrollo de procesos sociales y económicos similares y divulgadas a través de nuevos canales, favorecidos por la creciente movilidad de la sociedad y por las efectivas redes institucionales desarrolladas por una Iglesia católica con aspiraciones universalistas. A lo largo del siglo XII los territorios que conformaban la diócesis de Urgel experimentan una rápida sucesión de cambios en las estruc- 
turas sociales y económicas plasmadas en un incremento del dinamismo de sus modestos centros urbanos, paralelo a una creciente presión señorial sobre las clases populares y sobre las tradicionales estructuras de poder simultáneamente. Las tensiones generadas por estas situaciónes crearán unas condiciones propicias para la divulgación del nuevo ambiente espiritual, pese al hecho de no encontrarse entre las regiones más evolucionadas de Occidente y a su relativa lejanía de los principales centros de creación intelectual.

Las primeras manifestaciones de la espiritualidad evangélica en la diócesis de Urgel están relacionadas con el movimiento canonical. Las nuevas canónicas agustinianas, de gran proyección territorial en el ámbito que nos ocupa, recogen el ideal evangélico de la pobreza individual y de la vida comunitaria, siguiendo el ejemplo de Jesucristo y los apóstoles. Sin embargo, la propia popularidad de esta vía favorece un cúmulo de donaciones piadosas y un consiguiente enriquecimiento de las colegiatas que entrará en contradicción con los principios evangélicos que las animaban. Por otra parte, los recelos cada vez más firmes del episcopado hacia estas nuevas instituciones religiosas, vista su progresiva vocación de control de rentas y territorios que limita sus capacidades sobre grandes sectores de la diócesis, enfría el antiguo entusiasmo demostrado por la jerarquía urgelense en la promoción de nuevas fundaciones religiosas, que pone cada vez más trabas al asentamiento de nuevas órdenes en la diócesis y a su desenvolvimiento económico, tal como se desprende de los convenios establecidos con el orden del Temple en $1181^{7}$ o con el orden del Hospital en $1233^{8}$ en los cuales se acordaba una regulación de claro signo restrictivo en la percepción de las rentas por parte de los órdenes militares establecidos en las"parroquias de la diócesis de Urgel.

Las evidentes limitaciones que ponía de manifiesto la Iglesia en su capacidad de dar respuesta a las nuevas inquietudes espirituales dieron paso a nuevas experiencias más espontáneas, promovidas por los elementos más inquietos del laicado y con unos lazos cada vez más tenues con las instituciones eclesiásticas, hecho que no dejaría de provocar tensiones. En este sentido, ła expansión de un fenómeno eremítico renovado por su estrecha vinculación a una mentalidad asistencial muy relacionada con la nueva espiritualidad evangélica, supone una de las expresiones más genuinas de esta realidad. Los escasos testimonios documentales nos dejan entrever cierta difusión de este fenómeno en la diócesis de Urgel en la segunda mitad del siglo XII. Si los estatutos de Paz y Tregua redactados en Perpiñán en 1173 nos hablan por primera vez de los sanctimoniales ${ }^{9}$ (literalmente, consagra-

Acu, Ldeu, I, fols. 251v-252r, doc. 868; fol. 280r-v, doc. 981; fol. 288r-v, doc. 1.015; ed. C. Baraut, "Els documents, dels anys 1151-1190, de l'Arxiu Capitular d'Urgell». Urgellia, 10, la Seu d'Urgell 1990-1991. págs. 7-349, doc. 1.766 .

ACU, LDEU, I, fol. $288 \mathrm{r}, n^{0} 1.014$

Gener Gonzalvo I Bou (ed.), Les constitucions de Pau i Treva de Catalunya (segles XI-XIII), Generalitat de Catalunya-Departament de Justicia, Barcelona 1994, doc. 14, pág. 70 
dos a Dios) junto con otras categorías de religiosos, y vuelven a aparecer en 1187 en otros estatutos específicos para el condado de Urgel ${ }^{10}$, nos consta la existencia en 1175 de una iglesia fundada al servicio de los pobres por parte de un matrimonio de villanos de Agramunt, bajo la advocación de Santa Magdalena, muy novedosa en la diócesis por aquel entonces, de procedencia francesa y de tradición eremítica ${ }^{11}$. También en el área pirenaica podemos localizar algunos hospicios localizados en pasos especialmente dificiles y orientados a la asistencia a los viajeros. Uno de los más antiguos de los que tenemos constancia es el Hospital del Baell, situado sobre la estratégica ruta que unía los territorios de Foix y Castellbò a través de las altas cumbres pirenaicas y mencionado de manera fugaz en un testamento del año $1170^{12}$. Si la vía eremítica llegaría a dar respuesta a muchas de las grandes inquietudes que atenazaban a los espíritus laicos más sensibles durante el siglo XII, también ejercería una influencia considerable en la sociedad mediante la creciente identificación de la entrega de los ermitaños con el espíritu verdaderamente cristiano, tan alejado de las prácticas del clero en aquellos momentos.

Otras cuestiones relacionadas con los nuevos estímulos espirituales se hacen patentes en la diócesis de Urgel a través de ciertas evidencias. La redacción del texto de las Homilías de Organyà, en el ámbito de la canónica agustiniana de esta población en 1204, compuesto en lengua romance, transmite cierta inquietud por el conocimiento directo de la Palabra de Dios, dejando de lado en este caso el empleo de una lengua litúrgica incomprensible para la mayor parte de la población. Por otra parte, la fundación del monasterio cisterciense femenino de Santa Maria de les Franqueses, cerca de Balaguer, en 1186 refleja la espinosa cuestión de la integración de la mujer en la vida religiosa.

Sin embargo, una vez determinada cierta incidencia de las nuevas corrientes espirituales en la diócesis de Urgel, no hay que exagerar el alcance de las mismas, puesto que la documentación del siglo XII es muy rica en testimonios que demuestran una gran pervivencia de unas formas y unas prácticas religiosas poco evolucionadas, sin el menor atisbo de interiorización, que seguían reduciendo la vida religiosa a una serie de prácticas bien calculadas y notablemente ritualizadas para obtener a cambio la protección de los poderes ultraterrenos y la garantía de la vida eterna. Ni siquiera el cada vez más virulento anticlericalismo aristocrático parece tener una correspondencia clara con estas nuevas sensibilidades, tal como se desprende del estudio de la obra del trovador Guillem de Berguedà, miembro de

Op. cit., doc. 16, pág. 85

ACU, pergamino suelto, $n .91 .064$, ed. C. Baraut, "Els documents, dels anys 1151-1190, de l'Arxiu Capitular d'Urgell», Urgellia, 10, la Seu d'Urgell 1990-1991, págs. 7-349, doc. 1.704.

ACU, fondo Caboet-Castellbo, doc. n. ${ }^{\circ} 20$, ed. C. BaRAut, “Els documents, dels anys $1151-1190$, de |'Arxiu Capitular d'Urgell», Urgellia, 10, la Seu d'Urgell 1990-1991, págs. 7-349, doc. 1.642. 
familia aristocrática y amigo del vizconde de Castellbò, el cual se dedicaba a denigrar a sus enemigos a través de sus versos satíricos y mordaces. En su obra existe un ciclo dedicado al obispo de Urgel, compuesta entre 1170 y 1175 , uno de los más violentos de toda su producción ${ }^{13}$. El interés de este ciclo desde el punto de vista que nos ocupa, es que nos aporta de primera mano la imagen que tenía el estamento nobiliario - de donde que surgen estos versos y al cual van dirigidos de forma prioritaria- de una jerarquía eclesiástica que competía decididamente con él por el control de las rentas. Sin embargo, a lo largo de estos versos no se percibe ni el menor atisbo de reproche por una vida poco ejemplar desde un punto de vista evangélico. Por más que se acusa al obispo de forma sucesiva y contradictoria de feroz violador de mujeres y de homosexualidad, el tono y el contexto de tales acusaciones están más orientadas a producir la hilaridad entre el auditorio que a reprochar su escasa calidad moral. No sabemos si ello se debe a motivos puramente estilísticos del propio autor o al reflejo de la escasa inquietud que merecían entre la clase aristocrática las nuevas formas de espiritualidad cristiana. Lo cierto es que si alguna inquietud de orden espiritual atenazaba a los miembros de la clase aristocrática pirenaica, perdieron una buena oportunidad de verla expresada en la poesía de Guillem de Berguedà.

Todo lo dicho nos permite suponer que la implantación de las nuevas formas de sensibilidad religiosa en la diócesis de Urgel durante el siglo XII fue limitada, adquiriendo sólo una cierta importancia en los centros urbanos más dinámicos y en las áreas de influencia de los principales establecimientos religiosos. Si no se puede negar una cierta capacidad aleccionadora entre la sociedad seglar de las principales manifestaciones de estos nuevos estímulos espirituales, no pueden explicar por sí solos la posterior caída de algunos sectores de la misma en la herejía. Por lo general, los planteamientos espirituales más radicales se expresan a través de una serie de experiencias que propician un alejamiento voluntario del mundo. En cambio, la ruptura neta con la Iglesia obedece a unos factores mucho más profundos, relacionados con el incremento a finales del siglo XII de una conflictividad social de naturaleza muy compleja, manifestada a través de un discurso de marcado componente religioso, que asume buena parte de los fundamentos espirituales del siglo XII en un sentido muy crítico y con un notable contenido social. La radicalización generada por este auge de las tensiones sociales a finales del siglo XII favorecerá la difusión de la herejía en ciertas regiones de Occidente, entre ellas el área pirenaica de Cataluña.

\footnotetext{
${ }^{13}$ Véase MARTi DE RIOUER (ed.), Les poesies del trobador Guillem de Berguedà, Quaderns Crema, Barcelona 1996, primera edición, poesias VII, VIII y IX.
} 


\subsection{La crisis finisecular}

La Cataluña de la segunda mitad del siglo XII experimenta, al igual que buena parte del ámbito europeo, la consolidación de un nuevo contexto socioeconómico, estrechamente relacionado con la expansión del tejido urbano y con el auge de la economía mercantil. El desarrollo de un nuevo grupo social vinculado al sector artesanal o al comercio, la progresiva integración de la economía campesina en un complejo sistema cada vez más subordinado al medio urbano o la expansión de la economía monetaria son los principales efectos de estas transformaciones que introducen una serie de matices dentro del orden feudal los cuales, sin llegar a amenazar su propia continuidad, generan nuevas tensiones sociales y económicas que promoverán importantes reajustes del sistema a corto y medio plazo.

Paralelamente, influido por el pensamiento de sus grandes prelados, el rey Alfonso II el Casto (1162-1196) asume una nueva concepción de la monarquía como una entidad de carácter público con una proyección sobre la totalidad del territorio, situándose por encima de los privilegios y de los tratos especiales obtenidos por sus grandes barones durante las décadas anteriores. Por ello, el rey se vería obligado a asumir una política muy costosa en términos económicos, de pactos, coacciones, amenazas y guerras para controlar e imponer su primacia a sus belicosos vasallos. La gran cantidad de recursos económicos requeridos por la hacienda real, incrementados por los gastos de una corte cada vez más suntuosa en un momento en el que se habían detenido las conquistas sobre el Islam, se tradujo en un aumento de la presión fiscal sobre el territorio mediante expedientes tan variados como el establecimiento de imposiciones de carácter general para todo el territorio o el recurso cada vez más frecuente de la alteración de la ley de la moneda. Todas estas circunstancias, coincidiendo con el cierre del drenaje del oro norteafricano hacia los reinos cristianos, y con la momentánea detención de la conquista sobre el Islam a causa del establecimiento de los almohades en al-Andalus, ponía en entredicho una de las tradicionales fuentes de beneficios de la nobleza norteña y, al mismo tiempo, incrementaba una tendencia inflacionista que perjudicaba especialmente a las clases urbanas y a los sectores más modestos de las clases rentistas, sobre todo la pequeña nobleza de caballeros y castlans, cuyo descontento permitiría nutrir las huestes de la alta aristocracia en las revueltas feudales que tendría que afrontar el rey Alfonso en los años ochenta y noventa del siglo XII.

Del mismo modo que la monarquía intentaba incrementar sus tradicionales bases de poder, los barones más poderosos del Principado supieron desplegar similares líneas de acción que les permitiría establecer unas bases territoriales más o menos amplias en las que respaldar su poder. Asimismo, el lujo de sus pequeñas cortes y los gastos derivados de la necesidad de mantener una nutrida clientela militar con la que asegurar sus dominios los puso en aprietos económicos. La forma más habitual de obtener recursos suplementarios fue el aumento de la presión sobre el campesi- 
nado de sus tierras y también el saqueo periódico de territorios vecinos, hecho que, en los territorios menos sujetos a la autoridad real originó una espiral de violencia que se enquistaría bajo la forma de pequeñas guerras endémicas.

La tensión generada por estas dos tendencias contrapuestas, aunque manifestada en buena parte del Principado, estallaría violentamente en las regiones más alejadas al control real, particularmente en el cuadrante noroccidental de Cataluña. La pervivencia de las antiguas dinastías condales de Urgel y del Pallars Sobirà excluían de la jurisdicción real grandes extensiones de esta región, limitada exclusivamente, y aun de forma muy matizada a causa de la presión de la pequeña aristocracia del país, a los antiguos condados de Cerdaña y del Pallars Jussà, incorporados al dominio real en 1117 y 1192 respectivamente. En esta región de la Cataluña interior la tensión feudal latente estallaría violentamente en la década de 1180 , bajo la apariencia de una confusa guerra civil que enfrentó a los principales poderes señoriales de la zona por la sucesión del condado de Urgel. Aunque la existencia aparente de dos bandos definidos en función a su adhesión a la causa del vizconde Ponç de Cabrera, aspirante a la dignidad condal ante la perspectiva de una sucesión femenina al frente del condado, o a la del conde Ermengol VIII de Urgel, que quería asegurar su sucesión en la persona de su hija Aurembiaix, la guerra, lejos de presentar un frente definido, se caracterizó por la agregación de antiguos conflictos feudales, de un alcance territorial limitado, en un conflicto de gran magnitud en el que cada cual eligió su bando en función tanto de sus propios intereses como de la opción tomada por sus adversarios.

La alineación de los grandes magnates pirenaicos en uno $u$ otro bando viene determinada por el antiguo contencioso mantenido entre la lglesia de Urgel y la familia vizcondal de Castellbò, a raíz de su lucha por el predominio político y social en la región. Los vizcondes de Castellbò eran los descendientes de los antiguos vizcondes de Urgel, titulares de este antiguo oficio administrativo de época carolingia. El cambio de denominación del linaje es consecuente con la progresiva concentración de sus dominios en torno al valle de Castellbò a lo largo del siglo XI, y también con la pérdida total de la anterior vocación pública de dicho oficio con la progresiva feudalización de las relaciones en el seno del grupo dirigente. Precisamente, el retraimiento de la autoridad condal y la progresiva consolidación de los dominios vizcondales en el valle de Castellbò, limítrofe con el núcleo central de los dominios de la lglesia de Urgel, coincide con los primeros roces documentados entre ambas entidades señoriales, hacia principios del segundo tercio del siglo XII. Sin embargo, este antiguo conflicto de mala vecindad adquirirá una nueva dimensión cuando en 1185 Arnau de Castellbò se case con Arnaua de Caboet. Arnaua era la heredera del patrimonio de la familia de Caboet, un linaje aristocrático con numerosas posesiones en las tierras altas del condado de Urgel que habia mantenido 
tradicionalmente buenas relaciones con la Iglesia diocesana. Desde mucho tiempo atrás, los señores de Caboet disfrutaban del dominio sobre los valles de Andorra en calidad de vasallos de los obispos de Urgel, y el último representante masculino del linaje. Arnau de Caboet, infeudó a la Iglesia la totalidad de sus dominios, distribuidos por algunos valles de la ribera derecha del alto y el medio Segre. Muerto Arnau de Caboet en 1170, el obispo Arnau de Préixens se apresuró a preparar el matrimonio de la heredera con un noble afín a la Iglesia, pero la muerte prematura de aquél propició la intervención del vizconde Arnau de Castellbò el cual, pese a la oposición de la Iglesia, consiguió casarse con la viuda en 1185, con lo cual el linaje de Castellbò conseguía trabar un extenso dominio territorial que abarcaba prácticamente todos los territorios de la parte alta del condado de Urgel de la orilla derecha del Segre. Con respecto a Andorra, el vizconde Arnau heredaría los derechos de los señores de Caboet, iniciándose una larga querella con los obispos que sólo hallaría un principio de solución con la firma del pareaje de 1278 , ratificado en 1288, que se convertiría en un precedente remoto de la particular naturaleza jurídica del Principado de Andorra. Esta nueva situación ponía en manos del vizconde de Castellbò una serie de territorios y de recursos que podian romper a su favor con el precario equilibrio que habían mantenido a lo largo de varias décadas con la Iglesia de Urgel, al tiempo que se convertia en el gran referente de la pequeña nobleza pirenaica, soliviantada por la insistencia de la Iglesia de Urgel en acaparar las rentas eclesiásticas en un momento en el que la crisis económica restaba poder adquisitivo a estas modestas clases rentistas y enardecía los ánimos.

Paralelamente, en la primera mitad de la década de 1190 , se produciría un acercamiento entre el vizconde y el conde Ramon Roger de Foix. El condado de Foix, de menor extensión que las grandes demarcaciones de Tolosa y Carcasona, colindaba con las tierras altas del condado de Urgel en su vertiente andorrana. Las relaciones entre los condados de Urgel y de Foix ya están documentadas de tiempo atrás. Sin ir más lejos, el obispo Bernat Roger de Urgel (1163-1167) procedía de la familia condal de Foix, del mismo modo que la condesa Dulce, esposa de Ermengol VII de Urgel. Pero estas relaciones se reproducían a todos los niveles: cuando los meses de verano permitían el tránsito a través de los puertos pirenaicos se activaban las relaciones humanas en ambos sentidos, motivadas ante todo por razones económicas.

Desconocemos las causas concretas que pudieron inducir al conde Ramon Roger de Foix, cuyo linaje se destacaría por una inquebrantable protección del catarismo en sus dominios, a establecer una alianza con el vizconde de Castellbò. Tal vez, en una visión a medio plazo, vio la oportunidad de extender su área de influencia al sur de los Pirineos o quizá, simplemente, se limitó a enrolarse en una aventura que prometía unos beneficios inmediatos que le permitirían reponer su hacienda tras su participación en la Tercera Cruzada. Sea como fuere, la intervención del conde de Foix y sus 
hombres como aliados de Arnau de Castellbò fue devastadora para las tierras altas del condado de Urgel y de la Cerdaña. En el verano de 1196, aprovechando posiblemente cierto grado de desgobierno tras la muerte del rey Alfonso II el Casto en abril de aquel mismo año, el conde de Foix irrumpió en la vertiente sur de los Pirineos con un ejército de mercenarios apoyado por Arnau de Castellbò y sus hombres, el cual se lanzó a una campaña de saqueo y destrucción sistemática sobre las tierras del Urgellet y la Cerdaña, culminando con la captura y el desvalijamiento de la catedral de la Seu d'Urgell, cuya obra se interrumpiria bruscamente ante el duro golpe que supuso esta acción para las finanzas diocesanas. Por más que la historiografía tradicional ha pretendido identificar al ejército de Ramon Roger de Foix con un ejército de herejes, alegando la saña que habian demostrado contra las posesiones de la Iglesia, conviene desmentir esta imagen que distorsiona enormemente la realidad. La acción del conde occitano más bien debe contemplarse como una manifestación de la mercantilización de la guerra de la mano de unos profesionales que venden su capacidad bélica al mejor postor. Estos mercenarios, que figuran en las fuentes con el nombre de ruptia$\mathrm{rii}^{14}$ ya habían azotado amplias zonas del reino de Francia a lo largo del siglo XII. Sin embargo, a juzgar por la enorme conmoción que causó la campaña de 1196, reflejada en la documentación de la época ${ }^{15}$, parece ser que se trataba de una forma de guerra a una escala hasta entonces poco habitual en estas tierras pirenaicas, cuyo encono contra las posesiones de la Iglesia tiene su origen, ante todo, en la codicia que despertaban unos templos que podían acumular grandes riquezas en especies, en moneda o bien en metal precioso tesaurizado bajo la forma de objetos litúrgicos. La campaña de 1196 fue tan solo el prólogo del establecimiento del linaje condal de Foix en las tierras altas del condado de Urgel, que se prolongaría hasta principios del siglo XVI. El matrimonio de Roger Bernat, primogénito del conde Ramon Roger, con Ermessenda, hija y heredera del vizconde Arnau de Castellbò, en la primera década del siglo XIII ${ }^{16}$, preparaba, a pesar de la intensa oposición de la Iglesia de Urgel, la unión dinástica entre las dos ramas aristocráticas. Tras la muerte de Ermessenda de Castellbò en 1230, la dinastía de Foix asumiría el dominio sobre el vizcondado de Castellbò junto con la tradicional hostilidad de sus titulares contra la Iglesia de Urgel.

\footnotetext{
${ }^{14}$ Pierre des Vaux De Cernay, Historia albigensium, c. 46, ed. Bovouet, Recueil des historiens des Gaules et de la France, XIX, Paris 1880, pág. 42.

${ }^{15}$ Los pormenores de la campaña son relatados con suma precisión en el Memorial dels danys donats per lo comte de Foyx y bescomte de Castellbò a la iglésia de Urgell. ACU. copia del siglo XIII, cuaderno en pergamino, fondo Caboet-Castellbò, n. ${ }^{8} 35$, ed. C. Baraut, "L'evolució política de la senyoria d'Andorra des dels origens fins als Pariatges (segles IX-XIII)". Urgellia, 11, la Seu d'Urgell 1992-1993, págs. 225-299, apéndice, doc. 1.

th Aunque se desconoce la fecha exacta de este matrimonio (Joaquim Miret i Sans afirma que se produjo con posterioridad a 1208, tras la muerte de Ermengol VIII de Urgel), el contrato matrimonial se firmó en la villa de Tarascón (condado de Foix) el 10 de enero de 1202.
} 
Pero volviendo al episodio de 1196, un estudio atento de la documentación nos revela que las acciones propiamente bélicas desarrolladas por las tropas del conde de Foix y de Arnau de Castellbò se acompañaron de numerosas violencias perpetradas por el pueblo llano también contra el clero y las posesiones eclesiásticas, particularmente en el antiguo condado de la Cerdaña, aunque también hay indicios de acciones similares en las tierras del Urgellet. De todo ello se deduce que la campaña militar contribuyó en alguna medida a provocar el estallido de las tensiones acumuladas durante las décadas anteriores por diversos sectores de la sociedad pirenaica contra la Iglesia de Urgel. Incluso en uno de los documentos referidos a la crisis de 1196 figura un tal Petro clerico que recibe las quejas de sus superiores por haber robado a los hombres del pueblo de Naüja, en la Cerdaña ${ }^{17}$. De hecho, y pese a la falta de un estudio que nos ilustre la situación del bajo clero pirenaico en esta época, hay que suponer que sufriría una suerte similar a la de otros pequeños rentistas afectados por la crisis económica finisecular, empeorada por el saqueo sistemático de los bienes del clero en la campaña del conde Ramon Roger de Foix en 1196. En varios paisajes del Memorial dels danys donats per lo comte de Foyx y bescomte de Castellbò a la iglésia de Urgell se refleja la situación de pobreza en la que quedaron muchos clérigos de la Cerdaña tras los saqueos realizados por las tropas de Castelibò y Foix, con pérdidas calculadas en más de tres mil modios de trigo y cinco mil sueldos. La Iglesia de Urgel, por su parte, perdió a lo largo de esta campaña en la Cerdaña, un total de diez mil sueldos. Sin duda, estas pérdidas significaron un duro golpe para las finanzas de la Iglesia en la cabecera de la diócesis de Urgel y tuvo consecuencias graves. El caso del párroco de Queixans, en la Cerdaña, que abandonó su parroquia a consecuencia de la miseria que siguió a la invasión de 1196 es revelador de una realidad ${ }^{18}$. A todos los niveles, la Iglesia se vio obligada a reestructurar sus bases financieras y su estructura del gasto, comenzando por el propio episcopado y el cabildo catedralicio, que se vieron obligados a interrumpir las obras de la catedral de la Seu d'Urgell por falta de líquido. Pero más allá de las obras de la catedral, el empobrecimiento de la Iglesia y la reestructuración de sus bases económicas tuvo que afectar a la solidez de los vínculos clientelares que, en base a su poder económico, habia establecido con ciertos habitantes de las ciudades y villas del área más afectada. En este sentido, es muy posible que la ruina de muchas parroquias se tradujera en el debilitamiento de muchas fidelidades. Finalmente, tal y como ya hemos observado en el caso de Petro clerico, es muy posible que algunos clérigos, preocupados por salir de su situación de miseria, adoptasen métodos moralmente dudosos, generalmente la apropiación indebida de bienes adscritos a la parroquia o al templo.

ACU, pergamino suelto, n. 1.207, ed. C. BARAUT, "Els documents, dels anys 1191-1200, de l'Arxiu Capitular de la Seu d'Urgell», Urgellia, 11, la Seu d'Urgell 1992-1993, págs. 7-160, apéndice, doc 74.

${ }^{18} \mathrm{ACU}$, Memorial dels danys..., fol. $4 \mathrm{v}$, ed. C. Baraut, "L'evolució politica de la senyoria d'Andorra des dels origens fins als Pariatges (segles IX-X|II)", Urgellia, 11, la Seu d'Urgell 1992-1993, apéndice 1, pág. 292. 
De este modo, a la ya tradicional hostilidad de la aristocracia hacia la Iglesia, se añadió un anticlericalismo creciente por parte de los estratos no privilegiados de la sociedad, ya latente en ciertos casos, pero incrementado por los efectos de la crisis finisecular. La nueva espiritualidad evangélica dotaría a este anticlericalismo espontáneo de un discurso ideológico que aportaría una clara visión del mal comportamiento de los clérigos y la jerarquía eclesiástica con respecto a los principios estipulados en los evangelios y que, llegado el caso, podría llegar a justificar la ruptura con una Iglesia de clérigos corruptos e inmorales, particularmente en el momento en que llegaran de la vecina Occitania unos religiosos de conducta intachable que propugnaran una nueva forma de espiritualidad y que aportaran la posibilidad de unirse a una nueva Iglesia alternativa.

\section{LA DIFUSIÓN DEL CATARISMO EN LA DIÓCESIS DE URGEL}

\subsection{Catarismo, haeretici y haeretica pravitas}

La historiografía moderna aplica el término catarismo a un amplio fenómeno histórico centrado en la evolución de una secta cristiana medieval de base dualista que propagó sus creencias por diversas regiones de Occidente durante los siglos XI, XII y XIII. Sus miembros, conocidos bajo las más diversas denominaciones según la época y el lugar, son identificados actualmente bajo el nombre de cátaros, vocablo que hecho fortuna y ha logrado una gran difusión para calificar a estos herejes.

Las dificultades de acotar y caracterizar este fenómeno ya se detectan en la propia Edad Media. Las dudas expresadas por los grandes prelados catalanes sobre el modo de proceder contra los cátaros en función de su grado de hereticalidad generan una nutrida correspondencia con la Santa Sede y con los principales intelectuales del orden de los dominicos, destacando entre ellos el gran jurista catalán Ramon de Penyafort, a lo largo de la cual se va fijando una jurisprudencia para actuar contra la herejía ${ }^{19}$. De la lectura de estas cartas se desprende que el problema no radicaba tanto en la determinación del castigo que merecían los herejes sino en el de todos aquellos que les apoyaban y les ayudaban en su empeño de difundir sus doctrinas heréticas puesto que, al fin y al cabo, los herejes propiamente dichos, conocidos dentro de la jerarquía cátara con el nombre de perfectos, eran aquéllos que habían recibido el consolamentum, y su número era tan reducido que en algunas ocasiones los creyentes catalanes tenian que ir a buscarlos en el Languedoc para poder realizar los rituales propios de la

\footnotetext{
"Los principales documentos generados a lo largo de esta correspondencia se hallan editados en C. Baraut, "Els inicis de la inquisició a Catalunya i les seves actuacions al bisbat d'Urgell (segles XII-XIII)", Urgellia, 13, la Seu d'Urgell 1996-1997, págs. 407-438, apéndice documental, docs. 5, 6, 7 y, especialmente, 8
} 
secta. Por ello, aunque la fuente del problema está en la predicación de los herejes, la verdadera gravedad del mismo estriba en la existencia de un entorno favorable que, sin haber roto abiertamente con la Iglesia romana, protege a los perfectos y, con ello, favorece la difusión de sus doctrinas apartándose de la obediencia de la jerarquía católica. El propio Ramon de Penyafort, en una carta dirigida al arzobispo de Tarragona en 1242, incluye en la lucha contra hereticam pravitatem toda una variada tipología de colaboradores y cómplices que, junto a los heretici, y a pesar de no haber roto con la Iglesia, deben ser también objeto de persecución y recibir una pena proporcional a su culpa. Dentro de esta relación se incluyen suspecti, credentes, fautores, receptatores, defensores y relaps ${ }^{20}$. Ello nos muestra que, a los ojos de sus perseguidores, la problemática de la herejía ya desbordaba ampliamente el grupo restringido de perfectos cátaros para abarcar a todo un entorno social, amplio y heterogéneo, sin el cual la herejía no podría haberse desarrollado.

\subsection{Las relaciones transpirenaicas y sus repercusiones ideológicas}

Si bien se han señalado las tensiones socioeconómicas autóctonas como factor decisivo de la ruptura social que favoreció la difusión de ideologías disidentes en la diócesis de Urgel, no podemos olvidar que las tensiones ideológicas creadas por la progresiva feudalización de las tradicionales estructuras de la Iglesia abririan el camino a nuevas aportaciones ideológicas foráneas de procedencia ultrapirenaica.

La permeabilidad de la cordillera y las estrechas relaciones establecidas entre las comunidades de ambas vertientes hay que remontarla, pese a la falta de estudios al respecto, a épocas muy antiguas. Sin embargo, es a lo largo del siglo XII cuando se concretan ciertas condiciones sociales y económicas que llevarán a intensificarlas y a diversificarlas notablemente. Por un lado, la presión demográfica en el lado occitano y el crecimiento de la economía mercantil lanzan grandes contingentes de población occitana hacia el sur, en forma de migraciones permanentes hacia las principales ciudades y villas del lado peninsular, particularmente las de los nuevos territorios ganados al Islam, o bien de forma temporal, para desarrollar ciertas actividades económicas puntuales, como el comercio o el trabajo a jornal, como puede ser el caso del pastoralismo transhumante, cuyas cañadas coinciden notoriamente con algunos itinerarios realizados por los herejes en Cataluña. La importancia que tienen estas corrientes de población en la difusión de nuevas ideas desde el sur de Francia radica en su capacidad de establecer un medio favorable a su divulgación, mediante la creación de am-

${ }^{20} \mathrm{BN}$, coll. Doat, $X X X V I$, fols. $226 \mathrm{v}$ y siguientes, ed. C. BARAUT, "Els inicis de la inquisició a Catalunya $i$ les seves actuacions al bisbat d'Urgell (segles XII-XIII)", Urgellia, 13, la Seu d'Urgell 1996-1997, págs. 407438, apéndice documental, doc. 8 . 
plias redes de solidaridad a lo largo de las principales rutas seguidas por el interior Cataluña, basadas en la comunidad de intereses económicos o de otra índole que tienen como principales puntos de referencia los centros urbanos de mayor actividad económica.

Paralelamente, la consolidación de los grandes linajes aristocráticos y la sistematización en torno a ellos de extensas redes clientelares vinculadas a través de los lazos feudovasalláticos, así como el progresivo afianzamiento del derecho de primogenitura, limita el margen de maniobra de un grupo reducido de grandes familias, atentas a establecer alianzas matrimoniales ventajosas y de prestigio, y también a asegurar el futuro de los descendientes menos favorecidos por el derecho de sucesión. Fruto de esta realidad es la política dinástica desarrollada por los condes de Barcelona sobre Occitania, excesivamente idealizada por cierta historiografía de corte nacionalista que en ella interpreta sin fundamento la existencia de un proyecto nacional de expansión sobre Occitania. Con todo, no es esta la única familia de la alta aristocracia catalana que intenta establecer lazos con familiares la nobleza occitana. A lo largo del siglo XII y también a principios del siglo XIII fueron varios los linajes catalanes, muchos de ellos procedentes del ámbito de la diócesis de Urgel, que establecieron vínculos de este tipo con sus homólogos ultrapirenaicos. Baste recordar los enlaces de Ermengol VII de Urgel con Dulce de Foix, de Guillermo de Montcada con María de Bearn, de Roger de Comenge con Guillema de Pallars o de Roger Bernat de Foix con Ermessenda de Castellbò. Dentro del grupo aristocrático catalán se percibe, ya en las últimas décadas del siglo XII, la influencia de las formas culturales propias de los ambientes cortesanos occitanos, particularmente de la poesía trovadoresca, con trovadores autóctonos de la talla de Guillem de Berguedà, Guillem de Cabestany o Ramon Vidal de Besalú, que componían en lengua occitana una poesía cortesana que, divulgada por los juglares entre los ambientes aristocráticos catalanes, recogía la voluntad de ruptura por parte de la nobleza con la hegemónica producción ideológica de la Iglesia, mediante la creación de nuevas formas culturales exclusivas de unas clases superiores laicas en pleno proceso de afianzamiento de su conciencia de clase. En cierto sentido, en estas cortes aristocráticas, el catarismo arraigará como una expresión más de esta cultura cortesana, tanto por su oposición con la postura oficial de la Iglesia católica como por cierta sintonía con algunas manifestaciones propias de la cultura cortesana, como una mayor sensibilidad hacia la realidad de la mujer.

En lo referente al ámbito eclesiástico, y dejando de lado las relaciones de corte institucional desarrolladas por el clero local con Roma o con las grandes federaciones monásticas de Cluny o de San Rufo de Aviñón, por citar las de mayor influencia en la diócesis, durante el siglo XII se desarrollan diversos vínculos también de signo religioso pero de mayor espontaneidad y ajenos a la actividad de las grandes entidades eclesiásticas. Lo forman una heterogénea tipología de personajes giróvagos, vinculados de algún modo 
con el estamento clerical, aunque a veces de una forma más bien tangencial, que atraviesan la cordillera en ambos sentidos por motivos muy diversos. Peregrinos, clérigos errantes, pobres o sin beneficio, estudiantes de paso hacia otras diócesis para recibir una mejor educación, y también ermitaños son algunos ejemplos de esta tipologia que no dejarian de tener su influencia a lo largo de las vías más transitadas. Desgraciadamẻnte, el silencio documental al respecto es casi total, y solamente de vez en cuando emerge algún dato que nos permite suponer la existencia de todos estos tipos en la diócesis de Urgel. La expansión hacia mediados del siglo XII de la advocación de origen francés de santa Magdalena, estrechamente vinculada con santuarios de tipo eremítico, podría considerarse como una manifestación de la influencia de estos religiosos giróvagos a nivel popular. En cierto sentido, este movimiento anticipa algunas formas de vida adoptadas por ciertas comunidades heréticas, como la predicación errante, la vida en la pobreza o. en ciertos casos, la voluntad asistencial. Es por ello que la predicación de los primeros herejes detectados en la diócesis de Urgel no presenta, aparentemente, ninguna solución de continuidad con esta realidad.

\subsection{Los primeros herejes de la diócesis de Urgel}

Las tesis de Jordi Ventura sobre la amplitud que alcanzó el fenómeno del catarismo en Cataluña suelen apoyarse en parte sobre su supuesta antigüedad, que el autor catalán llega a remontar hasta la década de 1160 en base a la hipotética presencia de una comunidad cátara dirigida por un obispo herético en el Valle de Arán. Este dato, aportado por una dudosa fuente del siglo XVII, ha sido puesto en cuestión por buena parte de los especialistas actuales, y además, desde un punto de vista geográfico, lingüístico y cultural, cualquier comunidad herética presente en dicho valle debería ser considerada como una remota extensión del catarismo occitano antes que como una precoz manifestación del catarismo catalán.

Descartada por lo tanto esta temprana presencia de la herejía en Cataluña, los primeros datos ciertos sobre la presencia de herejes en territorio catalán hay que buscarlos en la década de 1190. El testimonio más antiguo de la presencia de herejes en la Corona de Aragón lo hallamos en el decreto promulgado por el rey Alfonso II el Casto en el Concilio de Lérida de 1194, por el cual exige a todos los herejes de cualquier secta a abandonar sus dominios ${ }^{21}$. Dicho documento hace especial hincapié en los valdeses, que son designados también como pobres de Lyon y sabatatos, y amplia la condena al resto de las sectas heréticas, aunque se desconozca

AEG, pergamino suelto, armario III del claustro, est. a, transcrito en el Lhibre vert, $f .213$, ed. C. BARAut, "Els inicis de la inquisició a Catalunya i les seves actuacions al bisbat d'Urgell (segles XI-XIII)", Urgellia, 13, la Seu d'Urgell 1996-1997, págs. 407-438, apéndice, doc. 1. 
su número y su denominación. La especial atención a la secta de los valdeses, mantenida por el rey Pedro II en un nuevo decreto de condena emitido en 1198 que venía a ratificar el de su padre ${ }^{22}$, nos indica que eran éstos los herejes más temidos en la Cataluña de finales del siglo XII. Los valdeses eran seguidores de una secta cuyas manifestaciones más antiguas se detectan en el área de Lyon en la segunda mitad de la década de 1170. Recogiendo los principales impulsos espirituales de la cristiandad occidental del momento, los primeros valdeses adoptaron la pobreza voluntaria como forma de vida, y la predicación itinerante de la Palabra de Dios con el fin de continuar el proceso reformista de una Iglesia que se había distanciado visiblemente de sus fieles. Tolerados en un principio por la jerarquía católica, los valdeses fueron declarados herejes por el papa Lucio III en el concilio de Verona, en 1184. Sin embargo, la condena de la jerarquía católica contra los valdeses se fundamentaba únicamente en su negativa a acatar la jurisdicción eclesiástica y desobedecer la prohibición de predicar la Palabra de Dios sin el permiso expreso de dicha jerarquía. Se trataba, por lo tanto, de una condena de naturaleza puramente disciplinaria que no pudo evitar su consideración de buenos católicos por parte de amplias capas de la sociedad, mucho más receptivas ante la intachable forma de vida que demostraban aquellos predicadores errantes que hacia las sutilezas del derecho canónico. Por ello, durante la década de 1180 este movimiento se difunde muy rápidamente por todo el Languedoc, atestiguándose en la década siguiente su presencia en Cataluña, si bien en este último caso prácticamente todos los testimonios, surgidos de la legislación real, son muy genéricos y, en relación con la diócesis de Urgel únicamente conocemos la presencia concreta de los valdeses en las inmediaciones de la villa de Agramunt en el año $1200^{23}$. Sin embargo, la presencia de los valdeses al sur de los Pirineos, a pesar de ser constatada en sucesivas ocasiones a lo largo del siglo XIII, no produce series documentales tan relevantes como en el caso del catarismo, y sus apariciones se van diluyendo en menciones cada vez más ocasionales en la documentación inquisitorial. Ignoramos por el momento si ello obedece a una implantación menor en los territorios de la Corona de Aragón o a una menor atención prestada por los organismos represores de la heterodoxia, al no involucrar significativamente a ciertos sectores dirigentes de la sociedad, como sucedería con el catarismo.

\footnotetext{
AEG, ex archivio ecclesiae Gerundensis, ed. Marca Hispánica, ap. núm. 487, cols. 1.384-1.385, ed. C. BARAUT, "Els inicis de la inquisició a Catalunya i les seves actuacions al bisbat d'Urgell (segles XI-XIII)", Urgellia, 13, la Seu d'Urgell 1996-1997, págs. 407-438, apéndice, doc. 2.

"En un documento datado en julio de 1200 un clérigo de Puigverd de Agramunt jura al obispo de Urgel acatar sus sentencias y no apoyar a los herejes o inçabatatos (nombre que reciben popularmente los valdeses), ACU, copia del siglo XIII, LDEU, I, f. 269v, doc. 939, ed. C. Baraut, "Els documents, dels anys 1191-1200, de l'Arxiu Capitular de la Seu d'Urgell», Urgellia, 11, la Seu d'Urgell 1992-1993, págs. 7-160, doc. 1.904 .
} 
Los indicios más antiguos que nos hablan abiertamente de la existencia de contactos explícitos de la herejía cátara con Cataluña se remontan en torno al año 1214, y se localizan en el área septentrional de la diócesis de Urgel. Estamos hablando de los testimonios extraídos de dos documentos inquisitoriales en los que se relatan unos hechos acaecidos varias décadas atrás. El primero de ellos es el testimonio de Arnau de Bretós, miembro de una familia de la villa de Berga estrechamente vinculada al catarismo, capturado tras la caída de Montsegur en 1244. Cuenta Arnau de Bretós que unos treinta años antes de la fecha de su interrogatorio, es decir, sobre 1214, viviendo él en la villa de Berga, su madre Guillema de Bretós cayó gravemente enferma, hecho que impulsó a la familia a enviar a uno de sus miembros a Occitania en busca de un perfecto cátaro que pudiese conferirle el consolamentum. Una vez en Cataluña, se llevó a cabo el ritual de consolar a la moribunda para alcanzar una buena muerte, es decir, para morir dentro de la fe de los herejes. Seguidamente fue consolada Beatriu de Bretós, hija de Guillema de Bretós, en presencia de todos sus hermanos y sin la perspectiva de una muerte próxima, con lo cual entraba a formar parte activa de la secta herética. Los dos perfectos llegados de Occitania permanecieron en casa de la familia Bretós durante ocho días, pasados los cuales partieron nuevamente en dirección al norte de la cordillera ${ }^{24}$. A principios del siglo XIII, Berga era una próspera villa de mercado que estaba experimentando una notable expansión. Extendida a los pies del castillo, la ventajosa situación de la villa, ubicada en el curso alto del río Llobregat, en la zona de contacto entre las últimas estribaciones prepirenaicas y las comarcas de la Depresión Central, la colocaban en un estratégico nudo de comunicaciones entre los Pirineos, las llanuras centrales y la Cataluña litoral. Estos factores favorecerían una intensa actividad económica y un tránsito continuo de gentes de diversa procedencia que explican en parte la introducción y el fuerte arraigo que tendría el catarismo en esta villa que, por aquel entonces, pertenecía a la diócesis de Urgel.

Mucho menos abundante en detalles y también menos explicito es el segundo testimonio. En este caso, el personaje relacionado con la herejía es un miembro de la pequeña aristocracia pirenaica, el caballero Ramon de Josa, señor de un puñado de castillos ubicados al sur de la sierra del Cadí, a lo largo del valle de la Vansa. Sus buenas relaciones con el vizconde Arnau de Castellbò tienen su naturaleza en vínculos familiares complementados con una situación de conflicto permanente con la villa y el castillo de Tuixén, posesión eclesiástica que se erigía en el centro de sus dominios. Ramon de Josa fue un señor feudal relacionado con la herejía cátara durante toda su vida, hecho que le valió una condena póstuma por parte del tribunal de la Inquisición, siendo dictada la exhumación de sus

${ }^{24}$ BN, Paris, fondo Doat, vol. XXIV, tols. 182r-193r, ed. J. VenturA, “Catarisme i valdesia als Països Catalans", Actas del VII Congreso de Historia de la Corona de Aragón, III, 1962, págs. 123-134. 
restos y su expulsión del cementerio de los fieles. Ello ocurría en $1258^{25}$. En la sentencia de Ramon de Josa consta, junto con toda una larga lista de agravios contra la fe católica, su reconciliación con la misma ante el cardenal legado Pedro de Benevento. Dicho cardenal fue enviado en 1214 por el papa Inocencio III a la Corona de Aragón con el objetivo de organizar la regencia del joven Jaime I, entonces menor de edad, tras la muerte de su padre en la batalla de Muret en el año anterior. Aunque el documento no es muy explícito en cuanto a las circunstancias concretas de la reconciliación de Ramon de Josa, es muy posible que ésta se produjese con motivo de las Cortes reunidas en Lérida en aquel mismo año, que convocaron a todos los notables de Aragón y Cataluña, y que fueron presididas por el cardenal legado en nombre del joven rey. Cabe suponer, aunque la documentación tampoco lo manifiesta expresamente, que dicha reconciliación obedecia a la connivencia del caballero con los herejes, teniendo en cuenta que este dato encabeza una larga serie de agravios mantenidos por la Iglesia católica contra Ramon de Josa con motivo de su firme amistad con los cátaros a lo largo de toda su vida.

El análisis de estos primeros testimonios de la influencia del catarismo en la vertiente sur de los Pirineos nos habla, en primer lugar, de su origen occitano, bien explícito en el caso de la explicación de Arnau de Bretós. En el caso de Ramon de Josa, la pista occitana debería buscarse en su relación con la corte vizcondal de Arnau de Castellbò, bien relacionada, como sabemos, con el linaje occitano de los Foix. La procedencia occitana del catarismo catalán, corroborada en documentos posteriores, siempre ha estado bien asumida por la historiografía tradicional del catarismo en Cataluña. El aspecto que ha suscitado una mayor polémica ha sido la fecha de su introducción. Las evidencias de Ramon de Josa y de Arnau de Bretós hay que situarlas en torno al año 1214, y no parece que en aquel momento la presencia de herejes cátaros fuese una realidad muy extendida, como parece demostrar la necesidad del viaje a Occitania por parte de los miembros de la familia de los Bretós para hallar un perfecto cátaro. También se tendría que considerar la evidencia de los decretos de condena contra los herejes emitidos por los reyes aragoneses en los años 1194 y 1198 , en los cuales se denota un notable desconocimiento de la presencia en Cataluña de otra secta que no sea la de los valdeses, sin que deba achacarse este olvido a una supuesta política de persecución selectiva según la naturaleza de las distintas sectas heréticas, como se ha pretendido en algunas ocasiones.

Acu, Ldeu, II, doc. 68, fols. 71r-72v, ed. C. Baraut, "Presència i repressió del catarisme al bisbat d'Urgell (segles XII-XIII)", Urgellia, 12, la Seu d'Urgell 1994-1995, págs. 487-524, apéndice, doc. 12. 


\subsection{La lógica de la difusión del catarismo en la diócesis de Urgel}

El catarismo se difunde por las comarcas del sur de los Pirineos mediante la predicación de los perfectos cátaros a través de la tupida red de relaciones tendida a lo largo de las dos vertientes de la cordillera. No es descartable que los primeros contactos de los catalanes con la herejía se hubiesen producido dentro del ámbito occitano, atendiendo al sentido bidireccional de las relaciones establecidas entre ambos territorios, pero no conocemos evidencias documentales que corroboren esta hipótesis. La primera predicación conocida de los perfectos cátaros en de la diócesis de Urgel, como ya se ha explicado, se desarrolla en la villa de Berga y data de 1214. A partir de este momento los testimonios se vuelven más numerosos, siendo con ello posible establecer algunas pautas en la actividad pastoral de estos bons homes ${ }^{26}$ en el área catalana ${ }^{27}$. En primer lugar cabe destacar que de un total de catorce predicaciones conocidas entre 1214 y 1244 , casi siempre se desarrollan en un espacio privado, una casa particular la mayoría de las veces $^{28}$, aunque también puede ser la sala de un castillo, que no deja de ser el domicilio particular de un miembro de la nobleza, como aparece en dos testimonios que hablan de predicaciones heréticas en el capite castri de Josa, residencia del caballero Ramón de Josa y de su familia ${ }^{29}$. Solamente en un caso se hace mención de la existencia de un espacio público en el que los herejes podían predicar y realizar sus rituales, concretamente una casa en la villa de Castellbò quam tenebant ibi publice ${ }^{30}$, hecho que nos informa de la privilegiada situación que llegaron a disfrutar los cátaros en dicho lugar.

Paralelamente, estos mismos testimonios ponen de manifiesto la existencia de unos vínculos concretos entre los individuos que acuden a escuchar a los perfectos, siendo los lazos familiares los más habituales, tanto entre las clases no privilegiadas como en los ambientes aristocráticos.

Denominación que reciben los perfectos cátaros en los ámbitos occitano y catalán

Prácticamente hasta la fecha de la toma de Montsegur (año 1244) todos estos testimonios proceden del fondo Doat, destacando entre ellos, por la amplitud de sus vivencias y por su calidad de miembro activo dentro de la secta en territorio catalán, el de Arnau de Bretós (BN. Paris, fondo Doat, vol. XXIV, fols. 182r 193r, ed. J. Ventura, "Catarisme i valdesia als Països Catalans", Actas del VII Congreso de Historia de la Corona de Aragón, III, 1962, págs. 123-134) Otras deposiciones con testimonios interesantes sobre la actividad de los herejes en Cataluña en estas fechas son las de Dyas de Deine, la dama de Montaut (BN. París, fondo Doat, volumen XXIII, tols. 70v-75v) y Ramon Joan d'Abia (BN, París, fondo Doat, volumen XXIII, fols. 260r-273v).

En la deposición de Arnau de Bretós hay constancia de la acogida de cátaros en su propia casa de Berga en 1214 y de nuevo en 1234, en casa de Bernat Narbonés, en Vallporrera (en el área montañosa del interior de la archidiócesis de Tarragona) en 1243, y también en casa de Ramon de Gallicant, de Ramona de Gallicant, su madre, de Ramon Pastor y de Pere d'Urgell, todos ellos del mismo lugar de Vallporrera y hacia la misma época, asi como en casa de Carbonella de Sa Sentina, del lugar de Assasentil, no identificado pero localizado en Cataluña, también hacia 1243. Dyas de Deine, por su parte, nos habla de la presencia de herejes en casa de Arnau de Paris, en Castellibò, en el año 1224.

* Estas referencias al castillo de los Josa como centro de acogida de los cátaros aparecen en el testimonio de Arnau de Bretós y de Ramon Joan de Ábia.

צ: Según el testimonio de Arnau de Bretós. 
Las relaciones de naturaleza feudovasallática dentro de la clase dirigente constituyen otra tipología no desdeñable de los vínculos que relacionan a los individuos que asisten a los actos celebrados por los cátaros. En este sentido, abundan los testimonios de predicaciones cátaras en las cortes de Arnau de Castellbò y Ramon de Josa, siempre o casi siempre acompañados por diversos caballeros, vasallos o aliados en sus continuos enfrentamientos con la Iglesia de Urgel.

A partir del análisis de estos datos, podemos establecer un modelo de difusión del catarismo basado en la privacidad y en las relaciones personales. Del mismo modo que sucede en el ámbito occitano, son muy raras las adhesiones individuales a la herejía, inexistentes incluso en la documentación referente al área catalana. Todo parece indicar que la adhesión al catarismo se produce a partir del núcleo familiar y que es a partir de los vínculos con otros grupos familiares, bien en sentido horizontal (parentesco, vecindad, amistad) o vertical (lazos clientelares o feudovasalláticos), que se produce la difusión de la herejía.

Los testimonios más antiguos relacionan la presencia del catarismo en Cataluña con grupos familiares del ámbito aristocrático y de las clases medias urbanas, coincidiendo con los sectores sociales más descontentos con la Iglesia católica, bien por la competencia directa que despliega en la cuestión de la gestión de las rentas de la tierra, bien por el descontento de los espíritus más sensibles, generalmente vinculados directa o indirectamente al medio urbano, ante la baja calidad moral de sus representantes.

El núcleo duro del catarismo aristocrático en el Pirineo catalán se hallaba en la corte vizcondal de Castellbò, centro aglutinador del descontento nobiliario contra la Iglesia de Urgel. Aunque su vinculación con el catarismo no aparece documentada hasta el año $1221^{31}$, su estrecha relación con los ccndes de Foix y el peso que alcanzaría la villa de Castellbò en la organización de la Iglesia cátara en Cataluña nos inducen a suponer la precoz implicación del linaje de Castellbò con el catarismo, así como un notable protagonismo en su difusión por el estamento aristocrático pirenaico. Las condenas póstumas de los restos mortales del vizconde Arnau y de su hija Ermessenda ${ }^{32}$, nos explican que padre e hija, ésta última influida por el ambiente cortesano que conoció en Foix como esposa del que fuera conde Roger Bernat II, protegieron y favorecieron activamente la difusión del catarismo en sus dominios, y recibieron el consolamentum a las puertas de la muerte.

BN, Paris, fondo Doat, XXIV, fols. 239r-245r.

Ambas condenas fueron dictadas el día 2 de noviembre de 1269 por los inquisidores Pere de Cadireta y Guillem de Calonge (ACU, copia del siglo XIV, LDEU, II, f. 72v-74r, docs. 69 y 70, ed. C. BARAUT, "La presència i la repressió del catarisme al bisbat d'Urgell (segles XII-XIII)", Urgellia, 12, la Seu d'Urgell 1994-1995, págs. 487-524, apéndice, docs. 16 y 17). 
El vizconde Arnau de Castellbò se mantiene en el centro de un complejo sistema de solidaridades aristocráticas de las que se sirven los perfectos para divulgar sus doctrinas entre el grupo dominante de la sociedad. Junto al linaje vizcondal, uno de los más significados por su vinculación con la herejía cátara es el linaje de los señores del castillo de Josa. El caballero Ramon de Josa, miembro de una familia tradicionalmente hostil a la Iglesia de Urgel, se reconciliaría periódicamente con la jerarquía católica para volver a recaer en los errores heréticos de sus protegidos cátaros, comportamiento que le valdría una condena póstuma a manos de la Inquisición en el año $1258^{33}$. Su castillo de Josa también llegaría convertirse en un punto de referencia de primer orden para los simpatizantes de la herejia en el área pirenaica y prepirenaica. La estrecha vinculación de Ramon de Josa con el catarismo sería asumida también por su esposa Tímbors y su hijo Guillem Ramon. La vinculación de madre e hijo con la herejía aparece ampliamente relatada en la sentencia póstuma de Ramon de Josa, en la cual, a pesar de todo, el caballero Guillem Ramon de Josa obtiene el perdón real.

Junto a los Castellbò y los Josa, la documentación habla también de la vinculación de otros linajes menores de las tierras altas la diócesis con la herejía cátara, tras los cuales suele haber algún tipo de vínculo de tipo feudovasallático, familiar o de otra índole con la familia vizcondal de Castellbò. En lo que respecta a otros grandes linajes aristocráticos, solamente conocemos la implicación activa del conde Roger de Comenge, vizconde de Coserans y titular del condado catalán de Pallars desde 1229, en las guerras contra los cruzados de Simón de Montfort en Occitania, asi como una cierta actitud favorable a la herejía ${ }^{34}$, sin más consecuencias sobre su condado.

Por su parte, los principales centros urbanos de la diócesis urgelense experimentan, como sucede en buena parte de Occidente durante el siglo XII, un crecimiento sostenido que favorece la manifestación de tensiones motivadas por las contradicciones sociales que derivan del desarrollo de una economía monetaria y mercantil. Pese a que las evidencias de un catarismo urbano en la diócesis de Urgel son mucho menos numerosas que en el caso del catarismo aristocrático, hay constancia de actuaciones inquisitoriales de cierta envergadura en la villa de Castellbò en 1237 y en la de Berga en 1255 , así como indicios de otra actuación de características similares en la villa de Puigcerdà en 1238. Por otra parte, en un testimonio de 1250 se detalla la presencia de perfectos en las villas de Gósol, Solsona, Agramunt, Sanaüja e incluso en la misma Seu d'Urgell ${ }^{35}$.

Acu Ldeu, II, doc. 68, fols. 71r-72v, ed. C. BARAuT, "Presència i repressió del catarisme al bisbat d'Urgell (segles XII-XIII)", Urgellia, 12, la Seu d'Urgell 1994-1995, págs. 487-524, apéndice, doc. 12.

${ }^{34} \mathrm{ACU}$, pergamino original, carpeta $n .{ }^{\circ} 5$ del siglo XIII, $s / n$.

3. ACU, pergamino original, perdido; ed. Pere Pusol, Obra completa, Andorra 1984, págs. 31-32. 
El pequeño tamaño y el potencial económico más bien discreto de los centros urbanos del área noroccidental de Cataluña no favorecían el desarrollo de las abismales diferencias de fortuna que caracterizaba a los grandes centros urbanos de Occitania, el norte de Italia o Flandes. Sin embargo, ello no significa que fueran espacios libres de conflictividad social, originada en gran medida en la pugna entre las principales familias del lugar por el control del poder económico y político, en un modelo marcado por una acusada segmentación vertical de la sociedad y caracterizado por un sistema de solidaridades controlado por las familias más poderosas. En este contexto social, madurado a lo largo del siglo XII, la crisis finisecular introducirá nuevos factores de desestabilización a través de la merma sensible de los ingresos del clero y, por consiguiente, de su capacidad de mantener fidelidades y, en el ámbito pirenaico ante todo, de la extrema polarización de la sociedad en dos bandos a causa de las continuas luchas entre la Iglesia y la aristocracia feudal. Todo ello favorecería el claro posicionamiento de ciertos sectores urbanos frente a la Iglesia y sus amplios intereses económicos, en ocasiones contrarios a los de ciertos sectores del patriciado urbano, pudiendo adoptar un discurso evangélico radicalizado para justificar ideológicamente esta opción. Todo ello, en el seno de unas comunidades urbanas ya muy familiarizadas con las nuevas formulaciones espirituales del siglo XII, permite una progresiva apertura a las nuevas doctrinas de los herejes cátaros.

A partir de la caracterización de los grupos sociales más permeables a las nuevas formulaciones heréticas procedentes del sur de Francia, y siempre con el apoyo de las fuentes documentales disponibles, podemos dibujar las grandes líneas geográficas de penetración de las mismas. Las sociedades urbanas, con todas sus contradicciones y sus particulares líneas de fractura, ofrecen el medio ideal para la propagación de las nuevas doctrinas. Hay que recordar además que en la Cataluña noroccidental, estas sociedades están muy poco mediatizadas por una jurisdicción real abiertamente hostil a la herejía, a causa de la lejanía de los principales centros de poder, de la permanencia de las antiguas demarcaciones condales, o de una conflictividad social que merma la capacidad jurisdiccional del poder público. A grandes rasgos, los centros urbanos visitados por los herejes durante la primera mitad del siglo XIII, dibujan un itinerario jalonado por una serie de ciudades y villas que, iniciado en el antiguo condado de la Cerdaña, con la notable villa de mercado de Puigcerdà, se adentra por territorio catalán en dirección suroccidental, prolongándose hasta la ciudad de Lérida, el principal centro económico de la Cataluña occidental. Es interesante comparar este itinerario con una de las cañadas ganaderas definidas por el geógrafo Joan Vilà i Valentí a partir de sus estudios sobre la transhumancia en Cataluña a mediados del siglo XX, que unía los pastos de invierno de la Cerdaña con la ciudad de Lérida a través de la sierra del Cadí, pasando por las cercanías de Josa, Solsona y las tierras de la Segarra y de los 
Ilanos de Urgel $\left.\right|^{36}$, y más teniendo en cuenta que a principios del siglo XIV está documentada la vinculación entre la actividad transhumante y las últimas comunidades cátaras de Cataluña ${ }^{37}$. Sin embargo, no es la actividad transhumante por si misma la que favorece la dispersión del catarismo a lo largo de las cañadas ganaderas, sino la necesaria organización de contactos a lo largo de los centros urbanos que jalonan su trazado, desde las áreas de montaña hasta la llanura, proporcionando sus ferias y mercados el medio fundamental para sostener una actividad de tipo esencialmente mercantil, orientada al abastecimiento de carne para los crecientes centros urbanos y de lana para la industria textil, que sería ideal para la propagación de la herejía.

Significativamente, la villa de Castellbò, pequeño centro de mercado que se erigiría, bajo la protección de su corte vizcondal, en el núcleo principal del catarismo catalán, queda bastante alejada de este itinerario. La falta de concordancia de esta realidad con el modelo expuesto anteriormente se debe al matiz introducido en el área pirenaica por la alineación de la mayor parte de la clase dirigente aristocrática con la causa de los cátaros. La consecuencia es una penetración más intensa de la herejía en esta región norteña, implantándose en pequeños núcleos castrales y, a través de las líneas de influencia socioeconómica ejercida por los centros de mercado sobre su entorno, en los ámbitos rurales. De este modo, hallamos testimonios de presencia de cátaros en el valle de Castellbò en $1237^{38}$, en los valles de Andorra en la cuarta década del siglo XIII ${ }^{39}$ y en el alto Berguedà en $1250^{40}$.

\subsection{La Iglesia cátara en Cataluña}

La compleja malla de afinidades y solidaridades que conformaba el entorno del catarismo se basaba en una confusa maraña de actitudes y posicionamientos personales contra la jerarquía católica, aglutinada en torno a los perfectos, que eran los miembros de la casta sacerdotal que configuraba la Iglesia cátara. Cabe recordar que el número de perfectos siempre sería bastante reducido en relación a una masa de creyentes o de meros simpati-

36 Joan VILA I VALENTi, "La ramaderia a Catalunya", Geografia de Catalunya, vol. I, AEDOS, Barcelona 1958, pág. 453 .

Véase Emmanuel Le Roy Ladurie, Montaillou, aldea occitana de 1294 a 1324, Taurus, Madrid 1981.

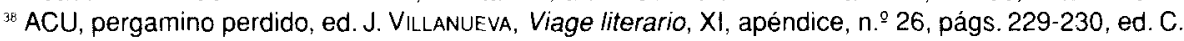
BARAUT, "Presència i repressió del catarisme al bisbat d'Urgell (segles XII-XIII)", Urgellia, 12, la Seu d'Urgell 1994-1995, apéndice documental, doc. n. ${ }^{\circ} 3$.

${ }_{39}$ Memorial dels danys donats per lo comte de Foyx y bescomte de Castellbó a la iglésia de Urgell. ACU, copia del siglo XIII, cuaderno en pergamino, fondo Caboet-Castellbò, $n .{ }^{\circ} 35$, fol. $6 \mathrm{~V}$, ed. C. BARAUT, "L'evolució politica de la senyoria d'Andorra des dels orígens fins als Pariatges (segles IX-XIII)", Urgellia, 11, la Seu d'Urgell 1992-1993, apéndice 1, pág. 295.

ACU, pergamino perdido, ed. Pere Pujol, Obra completa, Andorra 1984, págs. 31-32, ed. Baraut, "Presència i repressió del catarisme al bisbat d'Urgell (segles XII-XIII)", Urgellia, 12, la Seu d'Urgell 19941995, apéndice documental, doc. n. ${ }^{9} 9$. 
zantes que podía llegar a ser bastante numerosa. Pese a ello, los perfectos jugarían el papel crucial de canalizar el sentimiento de frustración de muchos fieles con respecto a la Iglesia católica hacia el nuevo referente espiritual brindado por la lglesia de los cátaros.

Como ya hemos podido comprobar, las primeras noticias de la presencia de perfectos cátaros en Cataluña remontan al año 1214 y nos hablan de la existencia de al menos una familia de creyentes en Berga, previa al establecimiento de perfectos de una forma estable sobre el territorio ${ }^{41}$. La primera noticia que nos informa de la presencia de una comunidad herética estable al sur de los Pirineos la hallamos en la deposición de Arnau de Bretós, quien afirma que en el año 1224 vio en la villa de Castellbò al diácono cátaro Guillem Clergue y a su compañero in domo eorum quam tenebant ibi publice ${ }^{42}$. Se trataba de una casa de perfectos, es decir, de uno de aquellos espacios de sociabilidad cátara por antonomasia, habitados y mantenidos por herejes, adonde se dirigían los creyentes, en ocasiones desde lejos, para escuchar las predicaciones o para solicitar los servicios religiosos de los perfectos. La presencia de casas de perfectos en la villa de Castellbò se prolongaría al menos hasta el año 1237, año en el que los informes inquisitoriales explican que se derribaron dos casas en la villa con motivo de la persecución operada contra los herejes ${ }^{43}$. Parece ser que la comunidad de perfectos de la villa de Castellbò, encuadrada en torno a estos establecimientos, estaba dirigida por un diácono ya en 1224. El hecho de que en el testimonio de Arnau de Bretós se explica que la predicación de dicho diácono se llevaba a cabo en su casa abierta públicamente en Castellbò, implica una presencia más o menos estable o, al menos, una autoridad vinculada con el papel preeminente de Castellbò con respecto a la herejía al sur de los Pirineos.

Ignoramos la existencia de otras casas de perfectos fuera de la villa de Castellbò, aunque el comportamiento de los miembros de la familia de Bretós, residentes en la villa de Berga, que tanto en 1214 como en 1229 y en 1234, deben ir a buscar a los perfectos a Occitania, Castellbò o Josa respectivamente para consolar a sus familiares moribundos ${ }^{44}$, nos indica que no existieron establecimientos de ese tipo en Berga, y posiblemente tampoco en Puigcerdà. En cambio, la reiterada aparición de herejes de alto rango en el castillo de Josa $^{45}$ y un nuevo episodio protagonizado por la familia de

\footnotetext{
4. Véase supra, pág. 25.

4. BN, Paris, fondo Doat, vol. XXIV, fols. 182r-193r, ed. J. VENTURA, "Catarisme i valdesia als Països Catalans". Actas del VII Congreso de Historia de la Corona de Aragón, III, 1962, págs. 123-134.

4. BN, Paris, tondo Doat, CLXX, fol. 75; ACU, pergamıno perdido, ed. C. BARAUT, "Presència i repressió del catarisme al bisbat d'Urgell (segles XII-XIII)", Urgellia, 12, la Seu d'Urgell 1994-1995, apéndice, docs. 1 y 3.

${ }^{44}$ BN, Paris, fondo Doat, vol. XXIV, fols. 182r-193r, ed. J. VenturA, "Catarisme i valdesia als Paisos Catalans", Actas del VII Congreso de Historia de la Corona de Aragón, III, 1962, págs. 123-134.

* Encontramos al diácono Pere de Corona en el castillo de Josa en 1226 (BN, Paris, fondo Doat, volumen XXIII, fols. 271r-271v) y nuevamente en 1232 (BN, París, fondo Doat, vol. XXIV, fols. 182r-193r, ed. J. VentuRA, "Catarisme i valdesia als Països Catalans", Actas del VII Congreso de Historia de la Corona de Aragón, III, 1962, págs. 123-134.).
} 
Bretós en 1234, según el cual se dirigieron a buscar a los herejes para consolar a otro familiar moribundo al capite castri de Josa nos sugieren la posibilidad de una presencia más o menos estable de los perfectos bajo la protección directa del caballero Ramon de Josa en su propio castillo.

A partir de estos escasos núcleos con una presencia de perfectos estable y bien conocida, la herejía llegaba a todos los rincones que contaban con simpatizantes reales o potenciales mediante contactos personales entre perfectos y creyentes. En ocasiones, los periplos de los perfectos para asistir a sus fieles podían prolongarse en el tiempo y en el espacio, como fue el caso del diácono Pere de Corona, el cual, procedente del concilio herético de Pieussa, visitaría a lo largo de tres años las comunidades heréticas de la Cerdaña, Josa, Cervera, Berga y la región de Siurana, en las montañas de la actual provincia de Tarragona, entre 1226 y $1229^{46}$, o el desarrollado por Arnau de Bretós, ya como perfecto ${ }^{47}$, por la misma región de Siurana durante el año anterior a la caída de Montsegur, en compañía de su socio Guillem Català. A lo largo de estos itinerarios, los perfectos se establecían durante un período más o menos prolongado en casa de sus simpatizantes. De este modo, las casas que cobijaban a los perfectos reproducían la función de una casa de perfectos, convirtiéndose en un punto de reunión para creyentes y simpatizantes del territorio circundante.

De los perfectos que operaron en Cataluña, la superioridad numérica de los de origen occitano nos indica un estrecho control ejercido por la Iglesia cátara de Occitania sobre las comunidades heréticas catalanas. Al igual que en el caso del condado de Foix, Cataluña no contó jamás con un obispo cátaro titular, dependiendo del obispado herético de Tolosa. En cambio, como ya hemos podido comprobar, en 1224 aparece documentada la predicación de un diácono cátaro en Castellbò. Dos años más tarde, se celebraba el concilio herético de Pieussa, que reuniría a unos cien perfectos cátaros procedentes de todos los rincones de Occitania. Entre ellos, se encontraba Pere de Corona, designado como diaconus haereticorum de Catalonia, el cual, una vez acabado el concilio, emprendería un largo viaje de unos tres años que le llevaría a visitar las principales comunidades heréticas de todo el ámbito catalán, desde el Pirineo hasta el área de Siurana, pasando por Berga, Josa y Cervera ${ }^{48}$. En 1232 la documentación vuelve a mencionar la presencia de Pere de Corona en el castillo de Josa ${ }^{49}$, aunque en este caso no se menciona su dignidad de diácono. El diácono cátaro de Cataluña, que tenía bajo su tutela las comunidades heréticas de un extenso territorio a di-

\footnotetext{
45. BN, Paris, fondo Doat, volumen XXIII, fols. 271r-271v.

47 Arnau de Bretós recibió el consolamentum en Montsegur en el año 1241 (BN, París, fondo Doat, vol. XXIV, fols. 182r-193r, ed. J. VENTURA, "Catarisme i vaidesia als Països Catalans", Actas del VII Congreso de Historia de la Corona de Aragón, III, 1962, págs. 123-134.).

${ }^{48} \mathrm{BN}$, París, tondo Doat, vol. XXIII, fols. 271r-271v.

4 BN, París, fondo Doat, vol. XXIV, fols. 182r-193r, ed. J. VentuRA, "Catarisme i valdesia als Països Catalans", Actas del VII Congreso de Historia de la Corona de Aragón, III, 1962, págs. 123-134.
} 
ferencia de sus homólogos occitanos, articulaba estas comunidades entre sí y actuaba de enlace con la jerarquía del norte de los Pirineos, tal como se desprende de su participación en el concilio herético de Pieussa.

Una vez consumada la rendición de Montsegur y la muerte o el encarcelamiento de la mayor parte de los herejes que habían hallado refugio en dicha ciudadela, la organización de la Iglesia cátara sufriria un duro golpe. En Cataluña la represión de la Inquisición contra el catarismo ya había comenzado en 1237 con la condena de numerosos herejes en Castellbò y la quema de dos casas de perfectos, y las actividades del Tribunal continuaron durante los años sucesivos. No conocemos ningún diácono de Cataluña posterior a Pere de Corona, la última noticia del cual, por otra parte, se remonta al año 1232. La sistematización de la persecución por parte de la Iglesia católica y el fuerte golpe dado a la organización eclesiástica herética en Montsegur impedirían una reorganización eficaz de la misma. El acoso continuo sufrido por los herejes fomentaria el desarrollo de una organización clandestina estructurada en base a las antiguas redes de solidaridad del antiguo entorno social del catarismo. Poco importará ya la dignidad de un perfecto dentro de la jerarquía de su Iglesia cuando, ante el número menguante de sus efectivos, lo realmente importante será su sola presencia, cada vez más esporádica, que aglutina ocasionalmente a los antiguos simpatizantes de cada comunidad.

\section{CONCLUSIONES}

Pese al carácter limitado del presente trabajo de investigación histórica sobre el fenómeno de la difusión del catarismo en Cataluña, a lo largo del mismo creemos haber podido establecer una serie de pautas básicas que deberian tenerse en cuenta en cualquier trabajo posterior que pretenda profundizar sobre el tema.

En primer lugar, hemos intentado matizar la extendida noción del fenómeno de la difusión de las doctrinas cátaras en Cataluña como un proceso impulsado desde ei exterior, concretamente desde Occitania, de un modo totalmente automático y sin la participación de la sociedad catalana, la cual se limita a aceptar unas doctrinas consideradas a priori superiores al discurso de la Iglesia católica. De este modo, hemos presentado a la sociedad de la vertiente meridional de los Pirineos como una formación dinámica, abierta a las nuevas propuestas ideológicas maduradas en Occidente, pero con unas tensiones y unas contradicciones propias que determinan la opción rupturista tomada por algunos sectores concretos de su conjunto, particularmente la clase aristocrática y las clases medias urbanas, ante la creciente competencia desplegada por una Iglesia católica de vocación terrateniente en el reparto de las rentas de la tierra. Esta realidad no sólo explica la introducción de las doctrinas heréticas en el área que hemos estudiado, sino que además permite caracterizar y acotar el fenómeno desde un punto de vista geográfico y social. 
En relación con esta última aseveración, estamos en condiciones de afirmar que el marco geográfico escogido para desarrollar el presente estudio, el cuadrante noroccidental de Cataluña, se convirtió en un área de privilegio para la difusión del catarismo, no a causa de la proximidad con las principales áreas contaminadas del Languedoc, o al menos no debido principalmente a ello, sino al hecho de que en este territorio se conjuminaban una serie de factores económicos, políticos y sociales que favorecerían esta realidad. Entre estos factores hay que remarcar la escasa capacidad de proyección del poder público en estas comarcas montañosas durante la Edad Media, factor que favorecería el desarrollo de una espiral de tensiones feudales en las que la Iglesia diocesana, volcada a la acumulación de rentas y patrimonios, se erigiría en una de las partes en conflicto, impulsando una aguda polarización de la sociedad en torno a cada uno de los dos estamentos de la clase dominante de la sociedad pirenaica: el eclesiástico y el aristocrático. Y ello por no hablar de las limitaciones de la capacidad represiva de los poderes públicos en estos territorios, que tan buenos resultados habian cosechado en la contención de las ideas disidentes en otras regiones mejor controladas. Evidentemente, todo ello no significa que fuera de esta región definida por la demarcación diocesana de Urgel no se escuchasen las predicaciones heréticas.

Finalmente, y dejando de lado las estériles polémicas sobre la importancia numérica del catarismo catalán que han caracterizado la escasa historiografía reciente sobre el tema en Cataluña, se ha intentado definir su incidencia real sobre la sociedad a partir del establecimiento de unos lazos muy diversos, flexibles y cambiantes, en la relación personal con la herejía, asi como un modelo de difusión basado en el grupo familiar como célula básica a partir de la cual se propaga aprovechando los lazos tendidos por determinadas formas de solidaridad.

Partiendo de estas conclusiones, las nuevas líneas de investigación sobre el tema deberían orientarse a establecer una visión global de lo que fue el fenómeno del catarismo en Cataluña, ampliando con ello el marco geográfico del presente trabajo al resto del Principado, principalmente a las áreas anteriormente citadas del interior de la provincia de Tarragona, y también el marco cronológico, para incluir los aspectos de la represión y de la pervivencia extrema de ciertas comunidades heréticas hasta principios del siglo XIV. 